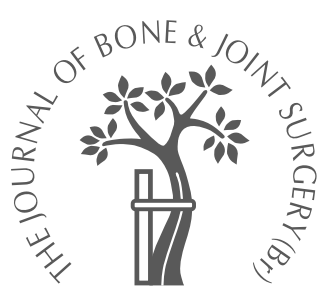
A. J. Shimmin,
D. Back

From the Melbourne Orthopaedic Group, Melbourne, Australia

A. J. Shimmin, MBBS, FA(Orth), Orthopaedic Surgeon

D. Back, BSc, MBBS, FRCS Ed(Orth), Orthopaedic Surgeon

Melbourne Orthopaedic Group, 33 The Avenue, Windsor, Victoria 3181, Australia.

Correspondence should be sent to Mr A. J. Shimmin; e-mail: ashimmin@ optusnet.com.au

(C)2005 British Editorial Society of Bone and Joint Surgery

doi:10.1302/0301-620X.87B4. $15498 \$ 2.00$

$J$ Bone Joint Surg [Br] 2005;87-B:463-4.

Received 24 March 2004; Accepted 4 May 2004

\section{Femoral neck fractures following Birmingham hip resurfacing}

\author{
A NATIONAL REVIEW OF 50 CASES
}

Between April 1999 and April 2004, 3497 Birmingham hips were inserted by 89 surgeons. Fracture of the neck of the femur occurred in $\mathbf{5 0}$ patients, an incidence of $\mathbf{1 . 4 6 \%}$. Complete data were available for 45 patients in whom the incidence was $1.91 \%$ for women and $0.98 \%$ for men. The relative risk of fracture for women vs men was 1.94961 and this was statistically significant $(p<0.01$ ).

The mean time to fracture was $\mathbf{1 5 . 4}$ weeks. In women the fractures occurred at a mean of $\mathbf{1 8 . 5}$ weeks and were more likely to have been preceded by a pro-dromal phase of pain and limping. In men the mean time to fracture was 13.5 weeks.

Significant varus placement of the femoral component, intra-operative notching of the femoral neck and technical problems were common factors in $85 \%$ of cases.

Birmingham hip resurfacing (BHR) has been carried out in Australia since 1999. There have been concerns about possible complications, in particular fracture of the neck of the femur following the procedure. ${ }^{1-5}$ It has been assumed that the majority of fractures occur early in the learning curve of the surgeon and within the first six to eight weeks after implantation of the prosthesis, but the incidence of this complication has not been established.

We carried out a national review of fractures associated with BHRs implanted between 1999 and 2003.

\section{Patients and Methods}

Between April 1999 and April 2003, 3497 BHRs were undertaken in 3429 patients by 89 surgeons; 2346 procedures were in men and 1151 in women.

All surgeons who have used the BHR arthroplasty, within Australia, were contacted by Osteoz, the suppliers of the prosthesis. They were invited to complete audit forms detailing any complications experienced in their practice. Information on outcomes following hip resurfacing is also prospectively collected by the Australian Joint Registry, and figures concurred with those of the Registry.

The review was performed by an experienced resurfacing Australian orthopaedic surgeon (AJS), and a further independent orthopaedic surgeon $(\mathrm{DB})$.

The details of the patients, relevant co-morbidities and the indications for operation were recorded via telephone and written communication with the treating surgeons. Radiographs taken before and immediately after operation and any further films taken before the fracture were analysed. The operative details recorded included the approach, size of the implants and difficulties experienced by the surgeon. The initial rehabilitation after operation and the subsequent management following the fracture were included. Surgeons were asked to state the order of the patients in their series in whom fracture occurred.

All data was collected and analysed using Excel spreadsheets (Microsoft Corp, Seattle, Washington) and SPSS 11.0 graduate package (SPSS Inc, Chicago, Illinois).

\section{Results}

There were 50 fractures of the neck of the femur during the study period with an overall incidence of $1.46 \%$.

Of the 45 femoral fractures with complete data, 22 occurred in women and 23 in men. The details of five fractures were not known. The posterior approach was used in all cases. The rate of fracture for women is $1.91 \%$, and for men was $0.98 \%$. The absolute risk of fracture in women was 0.0191138 and in men 0.0098039 . The relative risk for women $v$ s men was 1.94961 . This was statistically significant (chi-squared test; $p<0.01$ ). The difference in the complication rate between men and women is unlikely to have been due to sampling error. 
The mean age of the women was 56.17 years (25 to 70 ) and of the men was 62.05 years (30 to 72 ). The mean time to fracture was 15.4 weeks ( 0 to 56 ). Women fractured at a mean of 18.5 weeks ( 0 to 56 ) and men at a mean of 13.5 weeks ( 1 to 56$)$. This difference was not considered significant $(\mathrm{p}=0.3238)$.

Fractures of the neck of the femur had been encountered by 24 surgeons, two of whom were unable to contribute to the study.

Two fractures occurred during the operation. In one an attempt was made to fix it intra-operatively with a cannulated screw and proceed with the resurfacing procedure. This ultimately failed. In the other, a primary total hip replacement was performed.

Notching of the superior aspect of the neck of the femur was seen on the radiographs taken after operation in 21 $(46.6 \%)$ of the patients who subsequently fractured. Varus placement of the femoral component of more than $5^{\circ}$ when compared with the pre-operative femoral neck-shaft angle was seen in $32(71.1 \%)$ of those who fractured. Both notching of the superior aspect of the neck of the femur and varus placement of the femoral component was noted in 18 patients.

Technical difficulties were encountered by the surgeon in 11 cases including poor exposure due to obesity, a change in the intra-operative alignment and poor impaction of the femoral component.

We found no relationship between the experience of the surgeon and the time in their series when a fracture occurred. Surgeons who had performed more than 40 cases at the time of the incident experienced a total of 24 fractures. The earliest in the surgical learning curve was in the first case and the latest in the 224th.

We found no correlation between the size of the femoral component used and the rate of fracture. A 46- $\mathrm{mm}$ head was the most common used in women with a $50-\mathrm{mm}$ head in men.

Pain, with or without a limp, lasting from three days to two months, was noted in 21 cases. More women experienced symptoms before fracture (15), than did men (6). The remainder of the fractures were acute events. Of the 45 patients, 38 had been mobilised fully weight-bearing. The remainder had been allowed to weight-bear as pain allowed.

All fractures were treated by revision. During the study period there were a further 19 revisions, 12 for malposition of the acetabular component, four for aseptic loosening, two for infection and one for presumed metal hypersensitivity.

\section{Discussion}

There is an increased need for information about the complications and risks involved with hip resurfacing. ${ }^{6}$

Fracture of the neck of the femur has long been recognised as a major complication. ${ }^{1-5}$ Our survey has shown an incidence of $1.46 \%$ with the BHR, comparable with the rate of dislocation for a conventional total hip replacement. ${ }^{7}$ The factors influencing the occurrence of such a fracture can be divided into those of the patient, the operation and post-operative management.

Patient selection is of vital importance. The overweight, older female patient appears to have a greater risk of fracture. The importance of osteoporosis should not be overlooked $^{8}$ and a case may be made for routine DEXA scans before operation.

We were unable to show that fractures occurred more frequently in the early part of the learning curve of the surgeon. A combination of intra-operative notching, varus placement of the femoral component and poor exposure due to obesity were experienced at operation. Varus placement of the femoral component has been previously recorded as a risk factor for fracture of the neck. ${ }^{4,5,9}$ None of the fractures occurred when the femoral component had been placed in valgus compared with the pre-operative neck-shaft angle. Anatomical studies have shown that the compressive strength of the femoral neck relies on the medial trabecular system. Valgus placement of the femoral component optimises the load bearing capacity of the femoral neck. Varus placement increases the tensile stress on the superior cortex, increases the medial compressive forces and allows shear stresses to develop at the prosthesis-neck junction. ${ }^{4}$

Following the operation $84.4 \%$ of the patients who fractured were mobilised full weight-bearing, including 19 in whom a notch was visible on the post-operative radiograph. A recent case report suggested that non-operative management of minimally displaced peri-prosthetic fractures associated with hip resurfacing, can be treated conservatively with a successful outcome. ${ }^{10}$ It is likely that reducing weight-bearing in patients who show a notch in the neck of the femur after operation may lessen the risk of subsequent fracture.

We would like to thank all the surgeons, who have freely contributed their patients to the database, allowing an independent assessment of each individual case, thus helping to further our knowledge and experience of this complication.

No benefits in any form have been received or will be received from a commercial party related directly or indirectly to the subject of this article.

\section{References}

1. McMinn D, Treacy R, Lin K, Pynsent P. Metal on metal surface replacement of the hip: experience of the McMinn prosthesis. Clin Orthop 1996;329(Suppl):89-98.

2. Pollard TCB, Basu C, Ainsworth R, Lai W, Bannister GC. Is the Birmingham hip resurfacing worthwhile? Hip 2003;13:25-8.

3. De Smet KA, Pattyn C, Verdonck R. Early results of primary Birmingham hip resurfacing using a hybrid metal-on-metal couple. Hip 2002;12:158-62.

4. Freeman MAR, Cameron HU, Brown GC. Cemented double-cup arthroplasty of the hip: a 5 year experience with the ICLH prosthesis. Clin Orthop 1978;134:45-52.

5. Bell RS, Schatzker J, Fornasier VL, Goodman SB. A study of implant failure in the Wagner resurfacing arthroplasty. J Bone Joint Surg [Am] 1985;67-A:1165-75.

6. Australian Orthopaedic Association. National Joint Replacement Registry, annual report 2003.

7. Mahoney CR, Pellicci PM. Complications in primary total hip arthroplasty: avoidance and management of dislocations. Instr Course Lect 2003;52:247-55.

8. O'Neill TW, Lunt M, Silman AJ, et al. The relationship between bone density and incidence of vertebral fractures in men and women. J Bone Miner Res 2002;12:2214-21.

9. Freeman MAR. Some anatomical and mechanical considerations relevant to the surface replacement of the femoral head. Clin Orthop 1978;13:19-24.

10. Cumming D, Fordyce $\mathbf{M}$. Non-operative management of a peri-prosthetic subcapital fracture after metal-on-metal Birmingham hip resurfacing: a case report. J Bone Joint Surg [Am] 2003;85-B:1055-6. 